\title{
Institutional Development, Governance, and Ethnic Politics in South Sudan
}

\section{Madut Kon*}

The TAOS Institute, York University, Ottawa, Canada

\begin{abstract}
This article discusses ethnicity and socio-cultural complexity in governance, political systems, and bureaucratic institutions in South Sudan. Using the partially thematic and content analysis of the grounded theory analysis, the major themes and categories outline patterns of cultural norms and values in the absence of national identity that affects the pace of sustainable peace, economic development, good governance, and democratic transformation in the country. The outcome suggests that South Sudan continues to face multi-faceted socio-cultural, political, and economic challenges in its transition from ethno-centric system to viable democratic governance. This includes a genuine quest for nation-building transformation to a viable state, establishment of functional system, security, and rule of law and order in the country. The outcomes suggest that South Sudan Policymakers has paid minimum attention in eradication of poverty, high illiteracy rate and dogmatic ethnic values. Nonetheless, the country is in a dire need for traditional and cultural peace-building process among various ethnic-groups and communities as a corner stone for a sustainable socio-economic and political development.
\end{abstract}

Keywords: Ethnic politics; Governance; Indigenous society; Conflicts; Ethno-centrism

\section{Introduction}

Contemporary politics of South Sudan started with the AngloEgyptian Condominium form1898 to 1955. During this time, Britain and Egypt occupied Sudan, with separate bureaucratic arrangements for the north and south. Sudan became independent at the beginning of 1956 and faced long civil wars in the decades that followed [1]. From 1955 and 2005, northern and South Sudan experienced everlasting conflict and war. On 9 January 2005, the Comprehensive Peace Agreement (CPA) was signed by the SPLA/M and the NCP led government in Khartoum [2]. The CPA has granted semi-autonomy government to South Sudanese with a new Interim Constitution. Under the stipulations of the peace settlement, the SPLM leader John Garang was made the First Vice-President of the Republic of Sudan, and President of the Government of South Sudan. Three weeks only after being sworn into office in July 2005, John Garang died in an aircraft crashed and succeeded by SalvaKiirMayardit according to his seniority in the SPLM/A movement (ibid).

On 9 January 2011, Southerners voted on whether to become an independent nation or to remain part of greater Sudan. South Sudanese decided to separate from the north by more than 98 percent of the vote. On 9 July, 2011, the Republic of South Sudan was declared a sovereign country (ibid).

However, the process of building a cohesive national identity and new nation have yet to materialize in South Sudan due to the persistence of competing social and cultural factors, a high illiteracy rate among the populace, and the lack of well-trained political leaders (World Bank, 2010).

With the signing of the Comprehensive Peace Agreement (CPA) January $9^{\text {th }}, 2005$, many South Sudanese thought the absence of war would automatically bring about sustainable peace and development in their newly established country.

As such, it is noticeable that armed conflicts in many parts of the South Sudan can be attributed to lack of cohesive and coherent national agenda and policies for a sustainable development and livelihood exacerbated by politics of an identity deep-rooted in historic ethnic feuds [3]. Historically, South Sudan, like most countries in Africa, was a colonial invention during the European scramble for Africa when the European powers arbitrarily divided up Africa based on their interests with no regard to the geo-ethnic and cultural realities of the people [1]. As such, ethnic groups who were at some point traditional enemies found themselves within common boundaries defined as a region, province, or a township. Matters were further worsened when other ethnic groups, at the dawn of independence, started using ethnocentric divide-and-rule politics to settle scores under the excuse of law and order [4]. Since its independence, the South Sudan embraced ethnic rule, supported by the military, thereby weakening the establishment of the rule of law and order, as well as peace and security (ibid). This has delayed the creation and development of strong and credible state institutions in the country. The military systems of governance in South Sudan have undermined the concepts of civil society, multiparty democracy, and freedom of speech and movement due to lack of a permanent constitutional stipulations that safeguard these values(ibid). Nonetheless, the unresolved post separation issues with Sudan have led South Sudan to adopt profligate military spending. Hence, instead of social services and developmentprojects, the Government of South Sudan spent about 42 percent ( $\$ 555$ million) of its budgets on military procurements [5]. These figures may be higher as both SPLM-Juba and SPLM-IO continue to engage in an arms race and still have a complicated unresolved political dispute.

Apparently, investments in the arms race and worldwide oil crisis have led to divestment from other sectors of the economy, thereby affecting economic development and growth as the government deemed spending on programs such as education, agriculture, healthcare, and infrastructure as nonessential(ibid). These spending sprees not only restrained development projects but also held the socioeconomic

*Corresponding author: Madut Kon, Case Coordinator, Municipal Government The TAOS Institute, York University, Ottawa, Canada, Tel: +1416-736-2100; E mail: Kon.Madut@ottawa.ca

Received April 10, 2014; Accepted June 25, 2015; Published July 01, 2015

Citation: Kon M (2015) Institutional Development, Governance, and Ethnic Politics in South Sudan. J Glob Econ 3: 147. doi:10.4172/2375-4389.1000147

Copyright: (c) 2015 Kon M. This is an open-access article distributed under the terms of the Creative Commons Attribution License, which permits unrestricted use, distribution, and reproduction in any medium, provided the original author and source are credited. 
developments of South Sudan hostage to military manipulations and created the conditions for what is currently known as a failed state (Figure 1) [6].

The Fragile States Index 2014, also Placed South Sudan on the top of high risk countries of which highest points of measured factors that constituted such condition was placed on issues of Refugees and Internally Displaced Person (IDP), group grievances, fictionalized elite, human rights, human flight and legitimacy of the state. Other factors included quality of public services, poverty and economic declines, security apparatus, uneven development and external interventions. In total, South Sudan earned the highest points (112.9) making the country the most fragile state in the world.

Nonetheless, ethnic tensions like those in many African countries such as Somalia, Rwanda, Congo, etc., have become major challenges affecting the pace of peace and development in South Sudan. This is because communities and social groups identify themselves with tribes, cultures, villages, and regions as mechanisms of resistance and preservation of ethnic identity [7].

\section{The Construction of Ethnicity}

Decades of civil war between North and South Sudan helped to produce a collective perception of social, cultural, and political identity - known as "South Sudanese" - where the population thought of themselves as a homogenous society. Ethnic variations, cultural diversity, and ethnic divides along 65 ethno-tribal groups were not considered to be a ticking time bomb if not managed carefully in the nation building plan. This is because the construction of the South Sudanese identity was shaped by peoples' shared history of a common struggle to survive, and the preservation of African cultures from the eras of slavery; Turko-Egyptian rule in 1822, and British-Egyptian Condominium rule in 1898 to 1955 . This struggle continued through independence to the era of Arabization and Islamization adopted by successive central governments in Khartoum after the independence of Sudan in 1956 [8].

Several attempts were made during these foreign interferences to maintain ethno-cultural and tribal identities, one of which was manifested in the rebellion of Nuer and Azande ethnic groups against the colonial rule which resulted in the killing of British officers and Governor of Bahr El Ghazal in 1901 [9]. In 1930, the colonialists acknowledged southern Sudan as an ethnically and culturally distinct society, a concept that led to the total elimination of Arab influences and interests in South Sudan by 1940. This paradigm shift in the colonial politics and policies has lasted up to 1946, when it was then revised due to growing Arabs and Northern Sudanese influence in South Sudan and their resistance against the colonial policy of treating South Sudan as a distinct society [1]. However, the South Sudanese devoted many efforts to forming a country of their own in the Juba Conference in 1947, which was aimed to discuss the fate of South Sudan between unity with then Sudan or separation, the formation of the Liberal Party in 1955 with a renewed call for Federation in Sudan, and the Torit resistance which sparked the Anya-Nya civil war movement in 1963-1972 that ended with a semi-autonomous government in Southern Sudan. The last final push was that of the SPLM movement 1983-2005 which led to the settlement and successful independence in 2011 with signing of the Comprehensive Peace Agreement (CPA) in 2006 [10].

These synopses of historical events meant to provide a background on geopolitical factors that fostered unity of propose, and constructed common identity adopted by mostly by all African indigenous ethnic groups who are now known as South Sudanese. However, among these ethnic groups, the psycho-social prediction of peoples' interactions, identity, sense of belonging, and political thoughts are shaped by ethnic norms, clan and tribal affiliations, followed by region and individual's villages. For these reasons, ethnic feuds at local or communal level are easily transformed to the dynamics of power-sharing, political disagreement and ethno-tribal conflicts at the national level.

With all the ethno-cultural and political challenges, South Sudan gained its independence on July 9, 2011 after decades of war with Sudan in which about two million people perished, and an estimated four to five million people were internally displaced, while others took refuge in neighboring African countries, Europe, Australia, USA, and Canada. The independence of South Sudan, however, did not put an end to internal ethno-tribal clashes, rebellion, or the external border conflicts with Sudan [1].

Consequently, South Sudan continue to experience cycles of violence in forms of political rivalry, ethnic tensions, distrust between the government and the people, fueled by undisciplined ethnosized national army or better classified as armed militias [11]. The ten states in the country have at least experienced some of inter-communal violence, human rights issues, as well as dire economic condition and psycho-social well-being.

\section{Ethnographic Map of Ethnic Groups}

The people of South Sudan, as per an ethnographic map, have been classified as Nilo-Saharan of Eastern-Sudanic, with few identifying themselves as Bantus [8]. The people of South Sudanese were united by their determination to end policies of assimilation and divide-and-rule introduced by the Arabized Muslims of old Sudan since independence in 1956.

However, the missing narrative in the literature of ethnicity and ethnic grouping in South Sudan is that anthropologists and biologists assert that South Sudanese of the Nilo-Saharan origin are categorically kin by race and ethnic linkages [12]. Even so, it remains a challenge to promote such assertions even among the Nilotic themselves, or even creating an agreed upon national identity with a collective sense of cultural, ethnic, political, and common history of nation building. The perception of a self and group as a distinct ethno-tribal entity is much greater within the larger South Sudanese society, than any national symbols that may identify them as one nation.

South Sudan is home to 64 different ethnic groups. As per the census, there are still some disputes over the accuracy and reliability of the statistical data, especially the data gathered under the successive governments of Sudan before the independence of South Sudan. The first census that included South Sudan for the first time was conducted in 2008, of which its results was announced unilaterally by the Government of National Unity (GONU) in Khartoum, and rejected by the Government of South Sudan (GOSS). The named census sets the number of people in South at $8,260,490$, about $21.10 \%$ of the national average, of which about 520,000 of the South Sudanese population were cited living in North Sudan. The same census estimated population growth from 5,329,267 in 1983, to 8260490 in 2008. No mention was made of the internally displaced peoples (IDPs), refugees, and migrants in surrounding countries and abroad(National Bureau of Statistics, 2014). Authorities in South Sudan thought the number reported by the government did not reflect the exact number of people in South Sudan and their demographic characteristics. This was because government of then Sudan had no plans for any socio-political or economic 
development for the people or the region [13]. The Old Sudan policies were rather placed on social engineering and reconstruction of peoples' cultures and communities, through introduction of Arabic and Islam culture and religion to build(what was thought at the time by Northern Sudanese) a more homogeneous identity and society [14].

The ethnic distribution of South Sudanese groups can be better understood in the context of ethnic profile within the three regions of Greater Bahr el Ghazal, Greater Upper Nile, and Greater Equatoria. These three regions were established by colonial administration since 1920s and later redistributed into ten States by the Khartoum regime. Such clustering, coupled with the colonial policies of divide and rule have constructed sense of regionalized socio-political identity which in many aspect delayed conducive environment for a peaceful coexistence and socio-cultural and economic development, and most importantly contributed in cycles of regional political tensions in the politics of representation nationally. Table 1 below shows the ethnic variation in South Sudan, clustered by number of ethnic groups as per overall regional percentages and region of inhabitants (Table 1).

As illustrated, the number of ethnic groups in South Sudan varies by region. The three regions of South Sudan account for $65(100 \%)$ of the nation's ethnic groups. The Greater Equatoria Region accommodates 36 different ethnic groups, which account for $55 \%$ of total ethnic groups in the country. The Greater Bahr el Ghazal Region accommodates 21 ethnic groups, $32 \%$ of the total ethnic groups, and the Greater Upper Nile Region accommodates only 8 ethnic groups, 13\% of the total ethnic group in the country.

Within these ethnic variations, the $55 \%$ of ethnic and tribal communities within Greater Equatoria have managed to re-construct their multi-ethnic-group identities to a cluster of regionally based identity to be known as "Equatorian" socio-political arena rather than their ethnic or tribes of particulars. Apparently, the constructed regional identity of "Equatorians" is being mistaken to a tribe, rather than a monocular for a group of ethnic groups. The concept of Equatoriansas an identity is based on a cluster of 36 tribes that managed to construct a region of inhabitant as a common identity rather than ethnic affiliations. Bahr el Ghazal and Upper Nile regions have failed to recognize and adopt such regionalized identity over ethnic and tribal identity. However, a similar concept of groups identity and clustering has been also adopted among the Fertit groups of Western Bahr El Ghazal, a cluster of 14 ethnic groups that have managed to socially, culturally, and politically adopt a communal constructed identity known as "Fertits" rather than tribes of origins. The rest of Western Bahr el Ghazal ethic groups of Luo, Bongo, and Dinka remained distinct ethnic groups in the region.

In this context, the challenges of equitable ethnic representation in politics, governance, peace-building, harmony, and peaceful coexistence among ethnic groups have become major hindrances for nation building and conflict resolution in South Sudan. Highlighting the concept of clustering is quite useful for a better understanding of ethnic structure of the South Sudanese society and their perception of political and socio-cultural identity. Figure 1 below shows the ethnic groups variation by regions (Figure 2).

By examining the ethnic variation as shown (Figure 1) above, the Greater Equatorial region appeared to hosts the majority of the ethnic groups in South Sudan and have a better record of peaceful co-existence and mutually agreed upon clustered sense of identity [15]. However, it is worth noting that this majority is based on ethnic distribution, not the total population in the region per national capita. The Greater Bahr el Ghazal came second in numberof diverse ethnic groups hosted in the region, aswell, it hosts the majority of the Dinka ethnic groups in the country. The Greater Upper Nile hosts only eight ethnic groups and a home to the majority of Nuer ethnic group in the country.

\section{The Politics of Identity}

After its independence in July 2011, the SPLM ruling party and its leadership slipped into an ethno-centric approach of governance which depended heavily on nepotism and political appointments over skills and qualification of potential candidates. Such practice has led to a weak system of governance, political party and bureaucratic functions in the country. The adoption of ethnic-based practice also led to multi-faceted challenges and problems such as corruption, lack of rule of law, violation of human rights, ethnic exclusions, and ineffective mechanism of conflict resolutions and prevention [16].

Major cycles of this state of insecurity were witnessed in Jonglei State, Unity, Upper Nile, and some pockets in Greater Bahr El Ghazal and Greater Equatoria states. Many affected groups are the ethnic minority tribes who lack influence and equal representation in SPLM political party, government, and the military. It is equally true that the government, political parties, and the armed forces are ethnically dominated and structured along tribal alliances under an umbrella of (SPLM/SPLA) political party [11]. The mentioned systemic domination has been shaped by the history of tribal contributions and loyalty to the movement during the civil war between SPLA/M and the central government in Khartoum since 1983. In this scenario, other minority ethnic groups, who were used in counter-insurgency tactics on the Khartoum old Sudan side, have managed to join the new Independent South Sudan government through negotiated peace settlements with the SPLM ruling party. Those minority ethnic groups, who have totally rejected the new system, either formed opposition parties, or took up arm against the centralized SPLM/A led government in Juba.

The term politics of identity is used here in reference to ethno politics and other policies that are designed to be exclusionary and aimed to further the objectives of a selected few usually at the expense of the majority [17]. In South Sudan, the politics of identity has been adopted from successive regimes in the old Sudan which has successfully use it as means to divide and rule the country by creating a competing ideology tainted with a concept of us $v s$. them identity paradigm. In this context, religious sectarianism created frictions not only between Muslims and

\begin{tabular}{|c|c|c|}
\hline Greater Bahr el Ghazal & Greater Equatoria & Greater Upper Nile \\
\hline $\begin{array}{l}\text { Aja, Atuot (Reel), Balanda-Boor, Balanda-Bviri, Banda, } \\
\text { Bongo,Dinka (Jieng), Feroghe, GolloJur (Beli and } \\
\text { Modo), (Luo) } \\
\text { Mananger (Luo), Ndogo, Ngulngule, Sere, Shatt, Yulu } \\
\text { Kara, Binga, Indri, Mangayat }\end{array}$ & $\begin{array}{l}\text { Adio (Makaraka), Acholi, } \\
\text { Avukaya, Azande, Bai, Baka } \\
\text { Bari, Dongotona, Didinga, Ifoto, Kakwa, Lokoya, Lopit, } \\
\text { Lotuka (Otuho), Larim (Boya), Kuku, Lango, Logir, } \\
\text { Lulubo, Madi, Moro, Mundari, Pari, Pojulu } \\
\text { Nyangwara, Suri (Kachipo), Toposa, Imatong, Keliku, } \\
\text { Lugbwara, MoruMundu, Nyangatom, Tenet, Tid, Woro }\end{array}$ & $\begin{array}{l}\text { Murle, Nuer (Naath), Dinka } \\
\text { Shilluk (Chollo), Anyuak (Anyuaa), Jiye, Maban, Uduk }\end{array}$ \\
\hline Total: $21(32 \%)$ Ethnic groups & Total: $36(55 \%)$ Ethnic groups & Total: $8(13 \%)$ Ethnic Groups \\
\hline
\end{tabular}

Table 1: Profile of Ethnic Variation by Regions. 


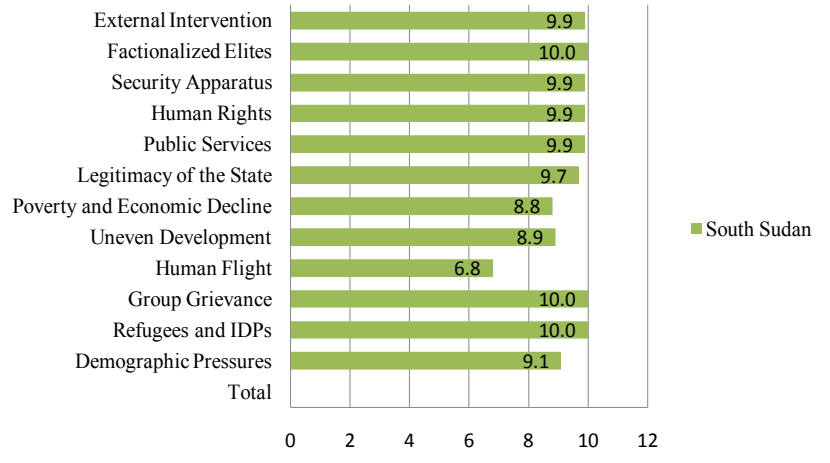

Figure 1: Fragile States Index 20141.

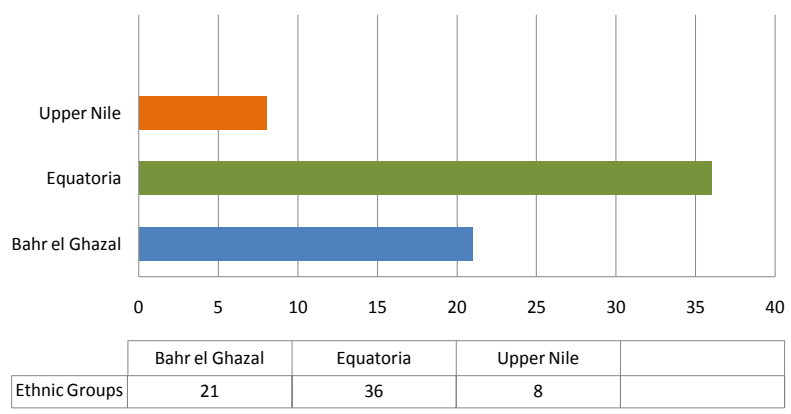

Figure 2: Ethnic representation by region.

Christians and also between Muslims who claim to be more Islamic than others in Sudan. Nonetheless, Arabism- an ideology that sought to promote Arab nationalism at the expense of the African identity was introduced as yet another racial divide mechanism that widened the gap between Sudanese Arabs and Africans in the South East and Western Sudan. In its genesis, these politics of identity have fractured Sudanese society so deeply that it resulted in conflicts between the central and marginalized ethnic groups in Darfur, Southern Kordofan, Blue Nile, Red Sea Hills, and South Sudan [1]. Therefore, it is fair to say that South Sudan has modeled the politics of identity adopted from Sudan after its independence and after deviating from the SPLM vision of rebuilding just and free democratic society. South Sudan is a country of over sixty tribes but only two ethnicities, Dinka and Nuer, dominated the government until the outbreak of December $15^{\text {th }}$ civil war and the subsequent massacre of the Nuers in Juba.

As a result, hiring practices now made on ethnic and tribal allegiances. Additionally, some in the SPLA/M claim to be more "SPLA/M Proper" than others because they claimed not to have rebelled against it and to have sacrificed more for the cause of freedom than others and as such feel entitled to government privilege [18]. Such ideas have not only led to rampant tribalism in the public sector but also incompetence and massive corruption that has interfered with development and service delivery thereby fuelling a growing discontent, unrest, insecurity, and instability in South Sudan(ibid).

${ }^{1}$ Fund for Peace (Feb. 2015). Fragile States Index 2014: Retrieved from. http://ffp.statesindex.org/
The politics of identity and tribalism are becoming challenges to South Sudan as both constitute triggers for potential divisions and undermining the fabric of the South Sudanese society. The politics of identity not only favor certain groups in South Sudan but also redefines the composition of South Sudan's society and construct the image of the country as being made up only of the two competing tribes (Dinka-Nuer). Nonetheless, these localized ethnocentric policies created suspicions, resentments and conflicts making it difficult to promote a national identity and socio-political cohesion.

\section{Equity, Representation, and Feud}

Due to the disputed numbers and conflicted views on projection of population in South Sudan, it is imperative that the government of South Sudan conduct its own census to obtain an accurate projection of the population in the ten states of the country. This will help create better plans for allocation of better services, equity, and fair distribution of resources. It will also eliminate the fallacies of communities' sense of entitlements because of being the largest as per their ethnicity, not over the national average of South Sudan population. The Dinka ethnic group has self-proclaimed their ethnic group to be the majority, and Nuer as the second majority against non-Dinka, and non-Nuer in South Sudan. Such perceptions led to a second era of marginalization and secondary citizenship of which the rest of 63 ethnic groups in South Sudan complained of power abuse, nepotism and discrimination.

The continuation of ethnic violence, political disputes, insecurity, corruption, marginalization and tribalism are in most cases associated with the two-dominant ethnic communities in South Sudan (DinkaNuer), otherwise known as the tribes of majority. Should the country adopt the working statistical figure of 2008 in Sudan, Dinka constitutes about $26 \%$ of the national average, Nuer with $24 \%$ and about $46 \%$ of South Sudanese ethnic groups are neither Dink nor Nuer. Therefore, in a fair democratic process, it would be difficult for the two tribes to claim a majority, or vote in members of their tribes based on their ethnic identities. However, the two ethnic groups have dominated of socio-political and economic affairs including the military powers in South Sudan.

In an equitable governance system, the fair share of the two ethnic majorities should have been $54 \%$ of the national average. The last KiirMachar's government was a clear example of political and economic power sharing and domination based on ethnicity and their historical rivalry to maintain peaceful co-existence between the two tribes (DinkaNuer). As a result, South Sudan slipped into its current conflict and has remained a volatile and fragile state. After the December $15^{\text {th }}$ crisis, the government has set its priorities on ethnic groups competing interest of tribal alliances to win the war, and not that of nation-building and socio-economic developments. In practice, South Sudan categorically adopted the same model of Arabized system of governance in the then-united Sudan of which only 35\% of Arabized Sudanese claimed ownership of the country, and marginalized $65 \%$ of its population. In this context, about 63 ethnic groups of South Sudan lives under the clemency of the two ethnic tribes of Dinka and Nuer, with the Dinka being the most dominant militarily, politically and economically. Many argue that the leverage of domination was brought into the play through over-representation of the Dinka ethnic group within the SPLM/A movement, and the negotiated peace settlements with the Dinka's traditional rivals, the Nuer who were over-represented in the counter-insurgencies and oppositions in Khartoum-led government(s).

Lack of socio-cultural and political will to address these competing tribal, regional, and ethnic interests has fuelled ethno-tribal conflicts 
which remained a major factor that hinders the nation's socioeconomic and political development.

New Section in here such as- Ethno-Political Rivalry in Localised Conflicts (Figure 2) below shows the framing of Grounded Theory (GT) and Situational Analysis (SA) to further illustrate perceived politics of identity and incidents of conflict among South Sudanese ethnic groups usually reported nationally and internationally. Among the 64 tribes of South Sudan, Figure 2 focused only on tribes that came into contact with other tribes in some form of ethno-political rivalry, land disputes or revenges reported on current active or inactive conflict within the regions of Greater Bahr el Ghazal, Upper Nile and Equatoria. According to Charmaz [19], grounded theory analysis is a process of naming each line of written data. With that coding process, I have also acknowledged Charmaz's statement that coding every line may seem like an arbitrary exercise because not every line contains a complete sentence and not every sentence may appear to be important. The thematic and content analysis of the grounded theory provided an opportunity for analysis of common incidents in similar situations, or different incidents in similar situations within the ten states of South Sudan. The process of analysis continued till all incidents were exhausted, or reached what is known as theoretical saturation in grounded theory, which is the stage where there is no further emergence of new themes from the data being analyzed [20]. The narrative was supported by statements from data collected to eliminate forced data analysis and bring the process closer to the stories reported. The Situational Analysis Matrix (SAM) was thereafter used in the form of Mind Map and Smart diagrams, which further facilitated analysis of the main themes and categories (Figure 3) $[21]$.

Ethnicity and tribal affiliation have been cited as an underlying cause of the ongoing inter-ethnic and political conflicts in the country. Major ethnic clashes reported in South Sudan since its independence were influenced by ethno-tribal, group cultures and their life style. The characteristics and mechanism of any conflicts reported in Bahr el Ghazal and Upper Nile regions involved some forms of ethnic factor. These ethnic factors are thereafter transformed to political and sociocultural conflicts in a form of wealth acquisitions (Cattle raiding), lands grabbing and displacements of rival ethnic groups.

Some of these conflicts were later transformed and understood as political rivalry due to the fact that large segment of the population are illiterate and do not meaningfully engage in political process nor

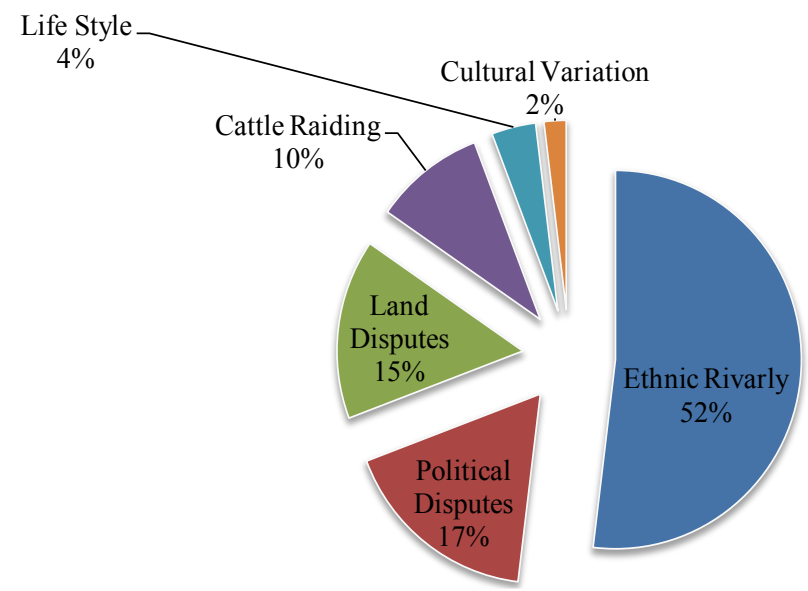

Figure 3: Reported incidents by causes of conflicts. understands it. Political rivalries were followed by land disputes due to wide spread of displacement within the country and resettlement of IDPs fleeing ethnic altercations, or military confrontation and counterinsurgency [3]. Other conflict has been attributed to ethnic and tribal groups who have adopted cattle raiding as a cultural practices or way of life.

\section{Leadership and Governance}

At the national level, it is noted that independence of South Sudan did not affect anticipated change in citizens' welfare nor strengthen political will to eradicate discrimination, marginalization and injustice. In addition to winning the title of a fail state, South Sudan track record for the last ten years has proven dismal in terms of tribalism, human rights abuses, corruption, as well as social disorder in all of its ten states [6].

Further, the adoption of ethnic identity among the rulers in South Sudan was interpreted by the minority ethnic groups as a divisive and exclusionary political tool and is designed to control and keep others away from centers of power [18]. Those powers should have been used to advance the common good or address the dire socio-economic development. In addition, such ideologies have fostered corruption, lack of accountability and self-centered ruling elites that elevate their interests above that of their countries.

In 2009, an estimated $47-51 \%$ of South Sudanese were under the national poverty line (World Bank, 2013). This high percentage of poverty is likely due to lack of sustainable development and limited livelihood opportunities after the independence [6]. Nonetheless, at the leadership's level, poverty eradication will require vision, planning, commitment and equitable investment.

To date, over $90 \%$ of the citizens of the South Sudan live in rural areas and made their livelihood directly from agriculture through forestry, farming, hunting and fishing thereby making it the single largest source of food supply and manpower [22]. However, lack of direct investment in agriculture and basic infrastructure of the South Sudan has ensured that this sector remains poorly serviced and rudimentary. As such, South Sudan face challenges in the provision of food security for a growing population within its newly created towns and localities. Lack of investment in agriculture and other private sectors of the economy have affected not only service delivery but also a potential to develop and improve the standard of living and export of local agricultural produce. Therefore, to improve the standard of living in South Sudan, there is a need for the governments not only to adopt the Millennium Development Goals [23] but also to move beyond poverty reduction and develop long-term plans and set goals for sustainable development and industrialization to expand their economic base.

In addition to inequality, maladministration, poverty, and underdevelopment also fuel cultures of corruption, insecurity, unrest, instability, and constant migration of an unskilled workforce from rural areas to urban centers. According to African Development Bank Group [24] interim country strategy paper, the South Sudan governments has no genuine strategies to eradicate poverty and underdevelopment, but are rather forced to deal with the consequences such as corruption, insecurity, unrest, and instability repressively without providing solutions to the problem in the first place. Therefore, to address the poverty and underdevelopment, the government of South Sudan need to divert spending from militaries to education, healthcare, infrastructure, food security and all or any services essential for basic needs. This will ameliorate the pressures on government in the short 
term as it will help increase employment and decrease discontent. The investment will also have an added advantage of increasing the tax base of the government giving the governments other means of generating more revenues.

As for justice system, there are no independent parliaments or judiciaries thereby severely limiting the roles these institutions play in enacting and enforcing law and order. The executive branches have overshadowed the legislative and judiciary and indeed seized the roles of the other two branches of governments. Consequently, then, presidential decrees have replaced legislations as sources of law and order thereby creating climates of uncertainties, limitations in law enforcements, and contradictions in governance. As well, South Sudan has yet to promulgate permanent constitutions. The absence of permanent constitutions has encouraged despotism, impunity, repression, misrule, and corruption thereby making it harder for the country to attract long-term investments (with exception of oil industries) because of the risk of instability. In short, the lack of a permanent constitution in South Sudan is detrimental to its political stability and economic development [25].

\section{Conclusion}

In conclusion, after the independence of South Sudan on July 9 , 2011 from the Sudan, politicians within the SPM ruling party diverted their attention from the core issues that triggered the rebellion against the successive governments in Khartoum and demand for separation. Even so, many Western nations, lead by the United States, have contributed massive financial, logistical, and technical supports to help with the efforts of rebuilding governance system and rehabilitations of basic infrastructures in country. These Western contributions yielded little in terms of moving South Sudan towards a viable country due to the long and unresolved history of ethnic conflicts, and its influences in socio-cultural, bureaucratic, and political institutions. It is therefore time for the policymakers and international community to shift their efforts from monitoring and reporting on government performance, to investment in human capital through skills development, peace building and peaceful co-existence, reconciliations and socio-cultural and economic development of people. The current style of ethno-centric governance in South Sudan that built on ethnic politics, dominations and representation based on tribal alliances continues to drag the country into an endless cycle of violence. This form of governance system in South Sudan will not foster process of nation-buildings, peaceful co-existence, or economic development in the country. As such, government priority should be place on eliminating cycles of tribal counter-insurgency, inter-clans disputes, cattle raiding and ethno-political rivalry. This can be done through ethnic reconciliations and social inclusions in all aspects of socio-economic development, genuine grass-root inter-ethnic reconciliations and promotion of peaceful co-existence. South Sudan will need to seriously transform these complicated barriers to cohesive social well-being and nation building through peace and social economic development. All efforts and resources should be invested in promotion of education, grassroot inter-ethnic and tribal reconciliations. Without addressing these divisive ideologies, South Sudan will continue to wallow in misrule mired by corruption, insecurity, underdevelopment, and poverty for decades to come.

\section{References}

1. Idris A (2013) Identity, citizenship, and violence in two Sudans: Reimagining a common future. Political and International studies collection.

2. About south sudan(2014) Malinume development Goal. UNDP.
3. (2010) Negotiating Sudan's north-south future. The International Crisis Group.

4. Odwar H, Gai S (2015) In Committee from the House of Commons Subcommittee on International Human Rights.

5. The World Bank (2007) Sudan public expenditure review synthesis report. Open knowledge repository.

6. Patricia T (2014) Statehood or Bust: The Case of South Sudan. Fund for Peace.

7. Roy WG (2001) Making societies: The historical construction of our world. Pine Forge Press.California.

8. Beshir MO (1984) Ethnicity, regionalism, and the national cohesion in Sudan Thousand Oaks. CA.

9. David de C (1995) South Sudan claims right of self-determination. University of Pennsylvania-African Studies Center.

10. Rolandsen $\varnothing \mathrm{H}$ (2009) Land, Security and Peace Building in the Southern Sudan. Oslo: International Peace Research Institute. The International Relations and Security Network.

11. UNMISS (2012) Incidences of inter-communal violence in Jonglei State. United Nations Missions in South Sudan South Sudan.

12. Robertshaw $P$ (1987) Prehistory in the upper Nile Basin. The Journal of African History 28: 177-189.

13. Deng FM, Gifford P (1987) The search for peace and unity in the Sudan. The Wilson Center Press, USA.

14. Markakis $\mathrm{J}$ (1987) National and class conflict in the horn of Africa. Cambridge University Press, Cambridge.

15. Gurtong (2015) South Sudan Peoples' profiles. Bringing south Sudan together.

16. (2015) South Sudan Seen as One of World's Most Corrupt Nations. Voice of America.

17. Gracia JE (2005) Surviving race, ethnicity, and nationality: A challenge for the twenty-first century. Rowman and Littlefield.

18. Madut J (2012) Diversity, Unity, and Nation Building in South Sudan. Washington, DC.

19. Charmaz K (2006) Constructing grounded theory: A practical guide through qualitative analysis. Sage Publications, California.

20. Clarke AE, Friese C (2007) Grounded theorizing using situational analysis. Sage Publications, UK

21. Denzin NK (2007) Grounded theory and the politics of interpretation.Sage publications, UK

22. Yongo-Bure B (2007) Economic development of southern Sudan. University Press of America, UK.

23. Hulme D (2009)The millennium development goals (MDGs): A short history of the world's biggest promise. Social science research network.

24. (2012-2014) South Sudan interim country strategy paper. African Development Bank Group.

25. (2015) Overview of corruption and anti-corruption in South Sudan. Transparency International. 